\title{
EXPRESIÓN DE UNA ESTÉTICA FORMAL FEMENINA EN CHRISTA WOLF: NACHDENKEN ÜBER CHRISTA T.
}

\author{
Montserrat Fernández Espinosa \\ Universidad de Zaragoza
}

\begin{abstract}
Christa Wolf's style in Nachdenken über Christa T. is indicative of a new direction in prose writing within the GDR. Clearly enough by means of this work Wolf is attacking the prescriptive mandates of Socialist Realism, first by focusing mainly on the experiences of GDR women and revealing their marginal position in the socialist state, second by calling into question the rigid linear forms and patterns imposed by the GDR cultural policy. Wolf's tendency to portray problems from the standpoint of specifically female experience urges her to find a new aesthetic form. In this article I analyse the several ways in which the authoress subverts the patriarchal model of reality based on dichotomous oppositions turning her prose work into a tool of social and personal emancipation.
\end{abstract}

\section{INTRODUCCIÓN}

Con la publicación en 1968 de la novela de Christa Wolf Nachdenken über Christa T. comienza en la antigua República Democrática Alemana una nueva prosa de tendencia emancipatoria ${ }^{1}$ que tendrá su máxima expresión en la década siguiente. Esta afirmación no viene avalada exclusivamente por el hecho de que el texto esté escrito, narrado y protagonizado por una mujer ${ }^{2}$, lo interesante en él es que la mujer pasa de ser el objeto imaginado a ser el sujeto que imagina ${ }^{3}$. Además, esta novela presenta la virtud de no contentarse con sacar a la luz las experiencias de las "sin voz" y desarrollar, en consecuencia, una estética formal adecuada a la experiencia femenina (Schmidt, 1982: 15556).

\footnotetext{
${ }^{1}$ Así lo afirman numerosas estudiosas del tema como: Ahlings, G./Nordman, I., «Arbeiten wie ein Mann und wie eine Frau dazu. Frauen in der DDR», Ästhetik und Kommunikation, 37 (Oktober 1979). Fehervary, H., «Die erzählerische Kolonisierung des weiblichen Schweigens. Frau und Arbeit in der DDR-Literatur», en: Grimm/Hermand (eds.), Arbeit als Thema in der deutschen Literatur vom Mittelalter bis zur Gegenwart (Königstein/Ts. 1979), 171-195. Herminghouse, P., «Wunschbild, Vorbild oder Porträt? Zur Darstellung der Frau im Roman der DDR», en: Hohendahl, P.U./Herminghouse, P. (eds.), Literatur und Literaturtheorie in der DDR (1976), 281-334.

${ }^{2}$ De hecho, tal y como indica Hassauer (1981: 712), autoras consagradas como Anna Seghers ofrecen en su prosa un modelo de mujer que se corresponde con el elaborado tradicionalmente desde una perspectiva masculina.

${ }^{3}$ Schmitz (1983: 293) recuerda que a la mujer le ha sido negada por tradición su capacidad artística, con lo cual su única relación con el arte -en este caso con la literatura- sólo podía ser como musa inspiradora, como figura objeto sometida a la voluntad del autor, o como simple receptora de la obra.
} 
Wolf libera a la mujer de su rol tradicional y la convierte en un sujeto con autonomía propia tratando temas 'peligrosos' y utilizando unas técnicas narrativas prohibidas por la política cultural de la RDA de aquellos años. Y es esta expresión formal basada en la distinta percepción que tiene la mujer de la realidad la que, de acuerdo con Clausen (1980: 320), se aceptó en la RDA como contrapartida al predominante discurso literario patriarcal.

Los problemas con los que las mujeres de la Alemania Oriental se enfrentaban a diario en su vida personal y laboral ${ }^{4}$ provocaron que surgiera una literatura que explora, expone y critica públicamente esas dificultades haciendo especial hincapié en lo distintas que son las prioridades que rigen la vida de una mujer de las de un hombre. Irigaray (1979) subraya que la mujer siempre ha sido definida acorde a unas dicotomías ${ }^{5}$ marcadas por el rígido y jerárquico orden patriarcal; el hombre determinaba la imagen de la mujer convirtiéndola en un objeto subordinado y dependiente de él, lo cual minaba notablemente la identidad femenina. Este nuevo tipo de prosa surge con la pretensión de definir a la mujer desde un punto de vista especificamente femenino, para ofrecerle una identidad con un sistema propio de valores.

Según lo expuesto, es así inevitable que existan diferencias entre la imagen de mujer que presenta una autora y la que pueda presentar un autor. Matheja-Theaker (1996: 168) explica que las autoras hacen uso de sus propias experiencias como mujeres para reflejar cómo les afecta la realidad, cómo se sienten ante determinadas situaciones. Prevalece, por tanto, la subjetividad: en otras palabras, la exposición de pensamientos y sentimientos. Esto no quiere decir que las autoras renuncien a la libertad creadora, pero lo ficticio siempre ocupa en sus obras un lugar secundario y el elemento autobiográfico se convierte en una constante.

Entre la autora y la protagonista se llega a establecer una relación muy íntima, a pesar de la inclusión de elementos ficticios (Schmitz, 1983: 204). Las dificultades, las insatisfaciones y las decepciones por las que atraviesan las protagonistas son las mismas que las de sus autoras, cosa que no se puede decir de los autores. Por ello, la mujer debe liberarse de esa imagen que no responde a su realidad y tratar de lograr una identidad autónoma reconociéndose en ese espejo que sólo puede ofrecerle otra mujer (Schmitz, 1983 : 272). Stanley y Wolfe (1978: 59) señalan que esta especial sensibilidad que aportan las autoras a la hora de interpretar el mundo real hace que tanto el lenguaje como la estética formal de sus obras difieran de los masculinos. El estilo femenino concede la máxima importancia al sujeto y así recoge todo tipo de ambigüedades y contradicciones; aparece la pluralidad de voces y perspectivas, la ruptura de dicotomías y la fragmentación; tampoco se olvida el mundo de los sueños como parte importante de la persona. La forma está al servicio de ese anhelo de construir una identidad propia. Jurgensen (1982: 485-86) atribuye a esta literatura de mujeres un efecto terapéutico, tanto para quienes la escriben, como para quienes la leen, ya que pretenden ayudar en el camino hacia la autorrealización.

\footnotetext{
${ }^{4}$ A pesar de que las leyes del gobierno socialista equiparaban la mujer al hombre ofreciéndole una educación, y, por consiguiente, la posibilidad de independencia económica, ésta -trabajara fuera del hogar o no- seguía ocupándose de las tareas domésticas, los hijos y el marido, lo cual hacía que su vida estuviera condicionada por presiones y falta de tiempo. Véase al respecto Matheja-Theaker (1996: 152), O’Brien (1985:41) y Schmitz (1983: 278).
}

${ }^{5} \mathrm{Hombre} / \mathrm{mujer}$, sujeto/objeto, inteligencia/sensibilidad, esfera pública/esfera privada, etc. 
Contrariamente, en los autores predomina la objetividad. Ven a la mujer desde fuera, no participan de sus vivencias, no se involucran, sólo conocen sus problemas de modo indirecto. La figura de la mujer se convierte así en un objeto en manos del autor. Los escritores tienen una imagen femenina preconcebida que dista bastante de la real. Construyen una imagen que responde al canon patriarcal y en todo caso muestran cómo debe ser la mujer y no cómo es realmente. Ajustándose a ese patrón, el resultado es un modelo utópico de mujer. Stanley y Wolfe (1978: 59) definen el modo de expresión patriarcal como sumamente objetivo, sin emoción ni opinión aparente. Los personajes son muy definidos y apenas experimentan cambios. En sus textos los acontecimientos transcurren en una sucesión cronológica lineal basada en la relación causa-efecto. Además, estos autores tienden a percibir el mundo en términos de categorías; las dicotomías son una constante debido a que los paradigmas convencionales aún subyacen en sus mentes.

Según Jurgensen (1982: 482), la mayoría de los autores germano-orientales, a pesar de mostrar en sus textos a una mujer socialmente emancipada, no solían reparar en los problemas que ésta continuaba teniendo al margen de la esfera pública. Por consiguiente, los escritores secundaban las consignas sociopolíticas sin molestarse en comprobar si éstas se llevaban a la práctica. Lo que pretendían en realidad era elaborar un modelo ideal para que las mujeres se adaptasen a él (Schmitz, 1983: 266). Todo ello hace evidente que en los autores domine lo ficticio.

En consecuencia, sólo cabe añadir que mientras que la literatura femenina tiene sus raíces en lo más personal, la escrita desde una perspectiva masculina es fundamentalmente utópica, porque —como pregunta acertadamente Jurgensen (1982: 483)— si la mujer está social y políticamente emancipada ¿cómo es que sigue buscando su autorrealización a través de la literatura? Es más, en el caso concreto de la RDA, la pregunta sería, ¿cómo es que en un país, donde la defensa de la igualdad entre mujeres y hombres estaba oficialmente reconocida, puede aparecer una obra tan crítica que abre la brecha de una literatura propia de mujeres basada en la denuncia?

A pesar de que en la RDA la mujer fue incorporada a la esfera pública como trabajadora ${ }^{6}$ (muy alejada del modelo patriarcal burgués en el que la labor de la mujer se reducía al ámbito doméstico), lo cierto es que su participación en el área intelectual política, periodismo, literatura, enseñanza universitaria, ...- era muy reducida (Herminghouse, 1976: 327). Es más, Morgner $^{7}$ — firme defensora del régimen marxistareconocía en una entrevista ${ }^{8}$ que, aunque la mujer trabajaba fuera del hogar al igual que el hombre, seguía siendo ella - en un $80 \%$ - la que se ocupaba de las tareas domésticas y de la educación de los hijos. Como señala Emmerich (1980: 108), a la mujer se la necesitaba como productora para ayudar al desarrollo económico del país; esto quiere decir que el

\footnotetext{
${ }^{6} \mathrm{La}$ teoría marxista exige la cualificación de las mujeres y su ingreso en el ámbito laboral para así garantizar la igualdad social entre ambos sexos.

${ }^{7}$ Irmtraud Morgner es una de las escritoras que en los años setenta toma parte activa en el desarrollo de una literatura de mujeres en la RDA. Su obra más conocida es la novela Leben und Abenteuer der Trobadora Beatriz nach Zeugnissen ihrer Spielfrau (1974).
}

${ }^{8}$ «Frauenliteratur oder Literatur von Frauen gemacht. Gespräch mit Jacqueline Benker-Grenz», en: Connaissance de la RDA, 10, Mayo 1980, pág. 61. 
estado sólo valoraba su aportación al conjunto de la sociedad y dejaba a un lado sus anhelos como persona individual.

Críticos literarios como Stephan (1979/80: 23), sin embargo, no observan en Nachdenken ... ningún tipo de problemática específicamente femenina. En su opinión, en la RDA no existía la necesidad de reivindicaciones en ese terreno, puesto que el estado ya se había ocupado de que la mujer tuviera los mismos derechos y deberes que el hombre. Sin embargo, Wolf, desde su perspectiva como mujer, nos demuestra que una cosa era la teoría y otra la práctica. La autora en este texto intenta examinar por qué no llegó a buen término la liberación de la mujer en el estado socialista (Lennox, 1983: 228). Christa T. representa la discrepancia entre el ideal y la realidad de la RDA.

En suma, la percepción de la sociedad que tiene Wolf como mujer es distinta de la del hombre y, por ello, como se intentará demostrar en este trabajo, su forma de expresión también mantendrá gran distancia con la estética patriarcal porque ésta no ofrece ninguna solución a la mujer.

\section{Christa Wolf y El Feminismo}

Hasta finales de los años sesenta la línea político-cultural prescrita en la RDA exigía a sus escritores que fueran educadores del pueblo. Siguiendo las consignas del 'realismo socialista' debían crear figuras literarias con carácter ejemplar que demostrasen su confianza en el estado y que, por supuesto, no tuvieran dudas ni contradicciones: heroinas y héroes positivos que habían de mover a imitación. Las obras debían ajustarse, además, al canon de literatura clásica ${ }^{9}$ — acorde a los valores tradicionalmente masculinos — utilizando técnicas narrativas comprensibles para los lectores ${ }^{10}$, con un final cerrado y feliz.

Con Nachdenken ... Wolf se enfrenta a la normativa del 'realismo socialista'. La protagonista no representa al conjunto de la sociedad. Aparece como un ser individual con sus dudas, temores, preguntas y contradicciones. Es todo menos un modelo a seguir. Christa T. no está integrada en la sociedad socialista; más bien ocupa una posición marginal, pero se trata de una marginalidad elegida por ella misma. La autora muestra el interior de la protagonista, y sus pensamientos y sentimientos delatan la poca confianza que ésta tiene en el socialismo propagado por el estado: el 'realismo socialista' utiliza al individuo como vehículo para estabilizar el país, sin embargo, el individuo en particular no es objeto de estudio. Esta novela persigue lo opuesto, realza la subjetividad y busca la autorrealización de la persona dentro de la sociedad.

Pero, ¿por qué escoge Wolf precisamente a una figura literaria femenina para enfrentarse a esa política cultural? En "Berührung" (1984a: 9) ${ }^{11}$ la escritora declara que la antología de Wander debe conducir a la reflexión y al cuestionamiento de la situación real de la mujer en la RDA. Aunque Wolf —como manifiesta en ese mismo prólogo (1984a:

\footnotetext{
${ }^{9}$ Se asocia a la teoría de Georg Lukács.

${ }^{10}$ La política cultural de la RDA dirigía una fuerte campaña en contra del 'formalismo', según la cual se rechazaba todo experimento literario. Dentro de una obra literaria debía primar siempre el contenido - acorde a los preceptos del régimen socialista- y las técnicas narrativas únicamente habían de favorecer su comprensión.

${ }^{11}$ Título del prólogo que Wolf escribe para la antología editada por Maxie Wander "Guten Morgen, du Schöne". Frauen in der DDR: Protokolle (1977). En este volumen antológico se recogen diecisiete testimonios de mujeres de la RDA. Las mujeres que hablan son muy representativas puesto que pertenecen a diferentes grupos de edad, a distintas profesiones y son de una procedencia social muy variada.
} 
12) - no comparte la idea de algunas feministas occidentales de que todas las mujeres pertenecen a una sola 'clase', sí que reconoce que su obra puede recibir el calificativo de 'literatura de mujeres' desde el momento en que considera que las mujeres perciben y expresan la realidad de un modo diferente de los hombres por factores históricos y biológicos (Wolf, 1983: 116). De acuerdo con esto, ella escribe desde una conciencia femenina con la pretensión de acabar con el silencio al que las mujeres han sido obligadas a lo largo de la historia: la mujer sin voz se convierte en una mujer que escribe para hacerse escuchar. En esta obra una mujer habla y expone su problemática particular sobreponiéndose a la falta de opinión. Desde esta perspectiva consciente de mujer la autora denuncia la falsa emancipación femenina dentro de la RDA.

Wolf (1980b: 63) no duda en declarar su escepticismo hacia una emancipación que no es otra cosa que una competencia simétrica de la mujer con el hombre: el mismo trabajo, el mismo comportamiento, el mismo éxito. Las esperanzas que se pusieron en este tipo de igualdad no se han cumplido porque exige la adaptación sin condiciones de la mujer al modo de ser masculino. La autorrealización de la mujer — entiende ella — no debe centrarse únicamente en el acceso de la mujer al terreno laboral, sino también en la conservación de los valores propiamente femeninos. En el prólogo a Wander (1984a: 17) la autora defiende el derecho de la mujer a hacer uso de todas sus cualidades y sentidos. A este respecto, Woolf en su polémico libro A Room of One's Own (1929) ya comentaba lo lamentable que resultaría que las mujeres escribieran como los hombres, que amaran como los hombres o que tuvieran el mismo aspecto que los hombres. En otras palabras, ¿por qué reducir dos géneros tan distintos a uno solo cuando el mundo se caracteriza por su variedad? Según Woolf, la educación debería sacar a la luz no las similitudes, que ya de por sí son demasiadas, sino las diferencias, e incluso reforzarlas.

Tal y como indica Schmitz (1983: 225), Wolf comparte con Woolf la defensa de una mayor diferenciación entre mujeres y hombres. La escritora considera esencial que la mujer preserve valores como la sensibilidad, la amistad, la solidaridad, la cooperación, la fantasía, la tolerancia y la valentía. En "Berührung" (1984a: 18) ésta reivindica el derecho de todo ser humano a vivir sin renunciar a ninguna de sus cualidades, y no lo dice con la intención de dar un paso atrás y caer de nuevo en los roles tradicionales, sino porque sinceramente cree que esas características femeninas son más valiosas para la persona que las típicas masculinas donde priman la racionalidad y el materialismo.

En la entrevista que Wolf mantiene con Kaufmann (1974: 108) proclama su rechazo al hecho de que la mujer intente igualarse al hombre hasta el punto de llegar a convertirse en otro hombre: "Ist es denn das Ziel der Emanzipation, kann es überhaupt erstrebenswert sein, dass die Frauen „werden wie die Männer”, (...), wo doch die Männer es so sehr nötig hätten, selbst emanzipiert zu werden?." Precisamente en el relato titulado "Selbstversuch"12 (1973) la autora incide sobre este punto de vista. La protagonista de esta historia es una científica que lleva a buen término el revolucionario experimento de transformarse en hombre. Sin embargo, su nueva vida le decepciona tanto que decide desistir y retornar a su identidad femenina. Este radical cambio de actitud en la protagonista se debe al descubrimiento de que los hombres son seres incapaces de amar debido esencialmente al

${ }^{12}$ Este relato aparece publicado junto con otros dos de temática afín en: Emmerich, Wolfgang (ed.), Sarah Kirsch, Irmtraud Morgner, Christa Wolf: Geschlechtertausch. Drei Geschichten über die Umwandlung der Verhältnisse, 
pragmatismo y a la falta de valores humanos que domina en sus vidas. Su conclusión es que los hombres no son ningún modelo a imitar.

Wander (1980: 208) afirma en su diario que la meta de las mujeres es sentirse realizadas como personas ${ }^{13}$; los hombres, en cambio, tienen otras aspiraciones, sobre todo alcanzar el éxito laboral. En consecuencia, el ideal de autorrealización de la mujer no consiste en una mera adecuación a los principios que rigen la identidad masculina, puesto que ésta sólo les proporciona inseguridad e insatisfacción como refleja la novela (Schmitz, 1983: 246). A la mujer germano-oriental le interesa autorrealizarse pero sin tener que dejar de ser ella misma.

A partir del particular modo de percepción femenina se configura una expresión formal que rehúye los preceptos patriarcales. Wolf explica que su rechazo a las técnicas narrativas tradicionales se debe a que están concebidas para que el autor se esconda detrás del material, convirtiéndo la obra en un mero objeto que trata a su antojo, dando así muestras de su falta de compromiso con ella y con los lectores (Kaufmann, 1974: 94). En "Berührung" (1984a: 12-13), la autora recuerda que desde el Romanticismo Temprano ${ }^{14}$ la mujer que escribe se ha decantado por géneros literarios tales como el diario, las cartas, los cuentos, los relatos de viaje y la poesía, que se corresponden con las formas más subjetivas; formas en las que la mujer se siente más libre y más a gusto para expresar su mundo interior. Por lo tanto, la subjetividad ha sido siempre parte esencial de las obras femeninas. También hay autores masculinos que utilizan la tendencia subjetiva, pero en ellos lo ficticio supera al elemento autobiográfico.

En «Lesen und Schreiben» (1984c: 26), Wolf define narrar como crear de manera realista a partir de la propia experiencia ${ }^{15}$. A pesar de no escribir desde un punto de vista feminista, la autora siente la necesidad de reflejar en sus obras la realidad según su percepción y experiencia como mujer (McPherson, 1979: 3). El profundo vínculo que la une con sus textos se observa por los numerosos sucesos autobiográficos que se narran en ellos, y Nachdenken ... no es una excepción. Tanto es así que, a veces, es imposible distinguir entre realidad y ficción. Las técnicas narrativas que utiliza ayudan a establecer esa relación subjetiva y no a evitarla. A esta constante presencia de la autora en su prosa Wolf le da el nombre de 'autenticidad subjetiva'. Lo que da a entender con esta expresión es que la obra debe corresponderse honestamente con la experiencia genuina y espontánea, configurando así una realidad alternativa fundamentada en la percepción femenina de la autora. Esta es la sensibilidad que la mujer y no tanto el hombre aporta a la literatura (McPherson, 1979: 9-10).

\footnotetext{
${ }^{13}$ Los años setenta son una época donde las mujeres empiezan a cuestionar la oportunidad que la sociedad les brinda de hacer lo que hacen los hombres y a preguntarse si realmente quieren ser como ellos: Was tun die Männer überhaupt? Und will ich das eigentlich? (Wolf, 1984a: 16).

${ }^{14}$ Momento a partir del cual la mujer comienza a ser valorada como escritora.

${ }^{15}$ En la entrevista que Karin McPherson (1979: 4) le realiza en Edimburgo, Wolf aclara lo que significa para ella el concepto de experiencia: "For me experience means everything that happens to a person, that is in this case a writer, not only what he actually experiences, but what he has thought and what has affected him, as well as any ideas he may have assimilated from ideology or literature or knowledge from any other field, in fact all those things that have come together to mould his mind, the way he thinks as individual. Of course that is autobiography too, but it is something more as well, the two concepts are related and mutually dependent, but they are not one and the same thing.
} 
Según Wolf, la literatura no debe presentar la realidad como si fuera un simple espejo; el papel de la escritora es fundamental en el proceso creativo puesto que evalúa críticamente esa realidad antes de configurar una nueva (McPherson, 1981: 9). La 'autenticidad subjetiva' demuestra el compromiso que ella tiene con su obra y los posibles lectores. La unión tan profunda entre la autora y su texto conduce, como ella misma confiesa, a que ésta termine identificándose con sus personajes, lo cual le ayuda a conocerse mejor a sí misma (McPherson, 1979: 7). Esto es lo que ocurre en Nachdenken ... donde Wolf se identifica con la protagonista y la narradora en primera persona. Así lo admite en «Selbstinterview» (1984b: 76-77): später merkte ich, daß das Objekt meiner Erzählung gar nicht so eindeutig sie, Christa T., war oder blieb. Ich stand auf einmal mir selbst gegenüber, das hatte ich nicht vorgesehen. Die Beziehung zwischen "uns" -der Christa T. und dem Ich-Erzähler-rückten ganz von selbst in den Mittelpunkt.

La literatura ofrece a Wolf un espacio para la expresión de una nueva forma de subjetividad más abierta y escribir se convierte para ella en un modo de explorar la relación entre subjetividad, identidad y lenguaje (Weedon, 1997: 241), que ya comenzó en Der geteilte Himmel (1962) y se afianza en obras posteriores como Nachdenken ... (1968), "Selbstversuch" (1973) y Kassandra" (1983).

Como explica la autora en «Lesen und Schreiben» (1984c: 47-48), la función principal de su prosa es la de marcar a las personas el camino hacia a sí mismas. De este modo, su narrativa se convierte en un medio de localizar los conflictos, los deseos y el potencial de la mujer (Hilzinger, 1980/81: 88). Escribir es, por una lado, el medio por el cual la mujer ha logrado romper su silencio histórico dando a conocer su problemática al resto de la sociedad y, por otro, como subraya en «Maßlosigkeit» (1980a: 61), se erige en un acto de resistencia a la mera 'adaptación social' y en un modo de búsqueda de identidad. Según Stephan (1991: 75), en Nachdenken ... la protagonista escribe precisamente como válvula de escape de sus sentimientos y como valla protectora contra las incomprensibles exigencias de la sociedad.

El vehemente deseo de escribir desde una 'autenticidad subjetiva', hace que Wolf utilice unas técnicas narrativas que no se corresponden con las impuestas por la teoría del 'realismo socialista' y que muestran mucho mejor la realidad conforme a su experiencia como mujer al integrar emociones e intelecto (Lennox, 1979: 218-19). De hecho, numerosas teóricas feministas estadounidenses opinan que Wolf, a pesar de no considerarse feminista, utiliza una estrategía formal que atiende expresamente a la subjetividad femenina (Lennox, 1983: 251).

En consecuencia, en Nachdenken ... las técnicas narrativas están en relación directa con el contenido subjetivo de la novela ayudando a descubrir la percepción femenina de la realidad. Rakusa (1984: 276-77) y Weedon (1997: 241) no dudan en afirmar que Wolf hace uso de una estética formal en la que aparecen lo que han definido como características inherentes a la estética femenina ${ }^{17}$ : subjetividad, dispersión del yo narrativo, distintas

\footnotetext{
${ }^{16}$ A este respecto, Siguán (1994: 139 y 148) destaca cómo Wolf reescribe el mito clásico para hacer de la portavoz de los dioses la primera mujer con voz propia.
}

${ }^{17}$ Estas peculiaridades formales -recogidas en las teorías de Hélène Cixous (1980) y de Luce Irigaray (1979)- no es que sean de uso exclusivamente femenino, por supuesto también hay autores masculinos que las utilizan. Lo que sí es cierto es que la mayoría de ellas son constantes o, cuando menos, bastante recurrentes en autoras (Rakusa, 1984: 289). 
perspectivas narrativas, polifonía, sustitución del principio de sucesión cronológica lineal por el de asociaciones, tematización del propio proceso de escribir, tendencia hacia un lenguaje muy próximo al oral, ausencia de comienzos y finales, ambigüedad, sintaxis paratáctica y simbolismo. Su modo de escribir, añade Weedon (1997: 241), es, en buena parte, un cuestionamiento de las formas de la narrativa autoritaria ${ }^{18}$.

3. EXPRESIÓN DE UNA ESTÉTICA FORMAL FEMENINA EN NACHDENKEN ÜBER CHRISTA T. La dificultad de decir yo - dieses fremde Ich (19) ${ }^{19}$ - a lo largo de toda la novela se refleja formalmente en el uso de técnicas narrativas basadas en la relativización y en la ambigüedad a que conduce la carencia de identidad. Además, la preocupación por mantener la 'autenticidad subjetiva, ${ }^{20}$ hace que las formas estéticas tiendan a la subjetividad y colaboren en la expresión del carácter inquisitivo de la obra.

\section{a) La doble posición de la narradora}

Wolf rechaza el concepto de narradora omnisciente ${ }^{21}$, sin por ello renunciar al derecho de la narradora a intervenir en el relato a través de comentarios, reflexiones o valoraciones. La posición de la narradora se encuentra a medio camino entre la distanciada narradora omnisciente ${ }^{22}$ y la narradora personal ${ }^{23}$ que participa directamente en los acontecimientos narrados (Thomassen, 1977: 35). Esto se explica porque el papel principal de la narradora en esta novela es el de recordar sucesos de los que ha sido testigo directo, bien en calidad de protagonista, bien de simple observadora (la historia narra buena parte de su propia biografía), con lo cual consigue una panorámica general de los acontecimientos: conoce el desarrollo y la relación que existe entre ellos, cómo terminan y cómo continúan influyendo. La narradora tiene la capacidad de poder observar todo desde una perspectiva alejada ${ }^{24}$,

${ }^{18}$ Hay que recordar que la teoría del 'realismo socialista' está elaborada de acuerdo con los valores tradicionalmente masculinos.

${ }^{19}$ Los ejemplos corresponden a: Christa Wolf, Nachdenken über Christa T., (München: Luchterhand, 1993). Las páginas aparecen entre paréntesis.

${ }^{20}$ Según la cual la realidad se presenta acorde a su propia experiencia como mujer.

${ }^{21}$ Aún cuando en numerosas ocasiones la narradora adopta una perspectiva externa a la protagonista -ocupando un lugar de observación privilegiado y, consiguientemente, disfrutando de un saber ilimitado- bien para escribir sobre Christa $\mathrm{T}$, bien para reflexionar en general, no llega a gozar de la prepotencia de una narradora omnisciente, puesto que su postura crítica tanto hacia la sociedad como hacia sí misma le obliga a relativizar y a cuestionarse todo, incluso cuando se dirige directamente a los supuestos lectores: Worüber können sie eigentlich geredet haben, gerade diese beiden, gerade zu jener Zeit? (102)

${ }^{22}$ Gracias a la perspectiva externa, la narradora omnisciente posee una libertad y un dominio del tiempo que le permite avanzar y retroceder sin limitaciones dentro del amplio espectro del tiempo del relato (Garrido, 1993: 130). Mediante esta movilidad temporal, continúa Garrido (1993: 130), se obtienen además nuevas modalidades de punto de vista: evaluación del presente desde el futuro, del presente y el futuro desde el punto de vista del pasado, pasado y futuro vistos a la luz del presente.

${ }^{23}$ En la situación narrativa personal el punto de vista de la narradora coincide con el de la protagonista, ya que la narradora asume su perspectiva temporal. En este caso la narradora se pliega, por exigencias de la perspectiva interna que ha adoptado, a las restricciones derivables de la ignorancia de la protagonista, por ejemplo, respecto del futuro (Garrido, 1993: 130). Veáse al respecto también Stanzel (1991).

${ }^{24}$ Da ich am Leben bin und sie nicht, kann ich bestimmen, worüber gesprochen wird, worüber nicht. (47) 
pero al mismo tiempo, al ser ella misma partícipe de esos sucesos, no puede saberlo todo, es decir, su conocimiento es restringido. En suma, nos encontramos ante una narradora "testigo-ocular" que puede limitar su relato a lo percibido con sus propios ojos o trabajar con lo que presumiblemente podría descubrir, y también aprovecharse de su propia fantasía. Es posible además que se presente como omnisciente y que asuma una mayor o menor distancia temporal respecto de los acontecimientos narrados (Garrido, 1993: 114).

El rechazo de la narradora a la omnisciencia objetiva y al control total de la obra, no hace más que subrayar las limitaciones del poder de percepción individual (Tate, 1984: 145).

b) Ruptura de la delimitación sujeto perceptor = objeto percibido

La relación entre la narradora y la figura central es bastante compleja porque se entremezclan el distanciamiento y la identificación, disolviéndose así la dicotomía tradicional presencia/ausencia del narrador.

La omnisciencia se amortigua por el gran relativismo que trae consigo la fusión del punto de vista de la narradora con el de Christa T., y ello hace que Hammerstein (1987: 27) señale entre ambas una relación de igualdad. Ese vínculo es tan íntimo que la narradora pierde su posición dominante y llega a identificarse con la protagonista.

A esto hay que añadir la innegable afinidad de la autora con la narradora. Las biografías de ambas casan hasta en detalles mínimos. Lo poco que se conoce de la vida de la narradora se corresponde con la de Wolf: la edad y su huída en 1945 de la región de Neumark a Mecklenburg cuando las tropas rusas invaden Alemania; las dos estudian Filología Alemana en Leipzig; ambas se casan y tienen hijos; su común afición a escribir, incluso las fechas en que terminan sus respectivas obras están próximas. Pero la autora también comparte con Christa T. un alto número de datos autobiográficos: desde el nombre de pila, la edad, los estudios, hasta sucesos que le ocurrieron realmente a Wolf ${ }^{25}$, pasando por su común afición a expresar los sentimientos a través de la escritura. Habitualmente lo que diferencia a la autobiografía de otros géneros, según Lejeune (1975: 137-162), es la implantación de un pacto, en virtud del cual los lectores establecen espontáneamente una relación de identidad entre autor, narrador y personaje a través de la forma discursiva yo y la firma estampada por el autor en la portada del libro. En este caso el alto número de coincidencias biográficas entre las tres mujeres practicamente obligan a los lectores a reunirlas en una sola identidad.

El solapamiento de identidades destaca su experiencia común como mujeres y escritoras (Hammerstein, 1987: 21). La narradora ${ }^{26}$ - y la autora - llega al punto de hacer suyas preguntas hechas anteriormente por Christa T ${ }^{27}$ Es más, el paralelismo entre estas vidas denota de nuevo el interés de la autora por preservar en su narración la 'autenticidad subjetiva', porque las experiencias que comparten la narradora y la protagonista pertenecen a la vida de Wolf. Tanto la narradora como la autora se identifican con Christa T., su

\footnotetext{
${ }^{25}$ Uno de los sucesos más escalofriantes que forman parte de la biografía de Christa Wolf y que la narradora atribuye a Christa $T$. es el de la muerte por congelación de un bebé al caérsele a Christa $\mathrm{T}$. de sus brazos mientras duerme a la intemperie durante la huída de las tropas rusas.
}

${ }^{26}$ Al fín y al cabo "el narrador es la imagen vicaria y voz delegada del autor" (Garrido, 1993: 111). 
relación es de igual a igual, nadie domina sobre nadie, y resaltan cualidades femeninas como la amistad y la solidaridad. Wolf convierte a la mujer en sujeto, dejando atrás la equiparación de mujer y objeto por la cual se le negaba a la mujer su opinión y participación (Hammerstein, 1987: 27).

\section{c) El juego entre la realidad efectiva y la ficción}

A pesar de lo dicho, Stephan (1991: 79-80) insiste en que por más que la autora introduzca datos autobiográficos para lograr la máxima credibilidad ante los ojos de los supuestos lectores, también es cierto que en ocasiones hace uso de su libertad artística para mezclar el mundo real con el fantástico. A este respecto, es interesante resaltar el pequeño prefacio $^{28}$ en el que Wolf advierte a los lectores de que Christa T. es tan sólo una figura literaria producto de su imaginación y que toda semejanza de los personajes y las situaciones que se describen con la realidad es pura casualidad ${ }^{29}$. Pero no tarda en contradecirse cuando en ese mismo texto asegura que las citas sacadas de los diarios, notas, poemas y cartas de Christa $T$. son auténticas. Wolf elimina así la tradicional e incuestionable frontera entre realidad y ficción, sumiendo a los lectores en un juego confuso en el que puede llegar a ser bastante difícil distinguir lo real de lo que no lo es (Hammerstein, 1987: 21).

Ocurre exactamente lo mismo con la narradora. Ésta tampoco vacila en confesar que hace uso de su imaginación allí donde su memoria no alcanza o donde el material dejado por Christa T. no le ayuda ${ }^{30}$, contribuyendo así a la inseguridad en los lectores. La estructura de la novela se basa en el recuerdo y como dice la propia narradora: Die Farbe der Erinnerung trügt (7). Es decir, el recuerdo es algo muy subjetivo y la memoria suele ser selectiva recordando sólo aquello que deseamos. Por ello y por la dificultad de presentar una realidad objetiva, la narradora reivindica la fantasía como parte fundamental de la verdad, sobre todo de la verdad literaria ${ }^{31}$ (Einhorn, 1978: 456). La narradora llega a la conclusión de que el objetivo de la literatura no debe ser la reproducción exacta de los hechos; si lo que se quiere es una imagen completa de la verdad hay que añadir las reacciones individuales a esos hechos y es ahí donde, en muchas ocasiones, interviene la libertad artística (Einhorn, 1978: 457).

Una muestra de ello es el episodio de la visita a Frau Dr. Dölling. Los lectores no son conscientes hasta el final del pasaje — abarca cuatro páginas - de que la conversación sólo ha tenido lugar en la mente de la narradora y eso gracias a que ella misma lo aclara ${ }^{32}$. Lo cierto es que si la narradora no hubiese confesado que la visita era mero producto de su

\footnotetext{
${ }^{28}$ Pág. 6.

${ }^{29}$ En otras palabras, parece ser que en un principio Wolf echa por tierra los esfuerzos denodados del narrador convencional por dotar de credibilidad suficiente a los hechos que constituyen el objeto del relato.
}

${ }^{30}$ Denn sie ist als Beispiel nicht beispielhaft, als Gestalt kein Vor-bild. Ich unterdrücke die Vermutung, daß es nicht anders erginge mit jedem wirklich lebenden Menschen, und bekenne mich zur Freiheit und zur Pflicht des. Erfindens. (47) (Subrayado mío).

${ }^{31}$ La narradora habla sobre was man erfinden mu $\beta$, um der Wahrheit willen. (48)

${ }^{32}$ Nein. Ich werde nicht zu ihr gehen, ich werde Gertrud Dölling nicht besuchen. Das Gespräch wird nicht stattfinden. (52) 
imaginación, el uso de los tiempos verbales ${ }^{33}$ no hace recelar de que ésta haya tenido lugar realmente. Hay veces incluso en que no se logra averiguar si las escenas son inventadas o no, porque la narradora no llega a aclararlo, son los lectores mismos los que deben decidir (Thomassen, 1977: 82-83).

Otra fuente de especulación son los materiales — diarios, cartas, notas, ... de Christa T.- en los que la narradora dice apoyarse para escribir sobre la vida de su amiga. Por un lado, nos habla de la autenticidad de esos materiales - tanto que cuando incluye en la novela alguna cita lo hace en cursiva - pero, por otro, hay veces en las que relativiza su autenticidad al igual que hace con su memoria ${ }^{34}$. De este modo, después de utilizar una cita del diario de Christa T. la narradora puede preguntarse: Und wenn sie ihn einfach erfunden hätte? (79).

La mezcla entre lo real y lo fantasioso también se manifiesta en los sueños que la narradora intercala a lo largo del discurso narrativo ${ }^{35}$ como si éstos fueran parte del mundo sensorial (alguno llega incluso a hacerse realidad), puesto que influyen en Christa T. de una forma $u$ otra. De hecho la narradora señala que su amiga "nunca ha logrado mantener separado aquello que no debe ir junto: los ilimitados sueños nocturnos y los limitados sucesos diurnos" ${ }^{\prime 36}$. Según ella, Christa T. era de las pocas personas en la RDA que no renunciaban a la fantasía porque es necesaria para la comprensión del mundo ${ }^{37}$. Es un modo más de hacer prevalecer la subjetividad, los sueños, los ideales y observar su correspondencia con el mundo exterior (Schmitz, 1983: 335).

La supresión de la frontera entre la realidad efectiva y la ficción contribuye a la relatividad y a la ambigüedad en la novela, pues el interés inicial por hacer creíble la obra no frena la tendencia hacia lo fantástico y así se vuelve a lo que Love (1979: 34) denomina una 'subjetividad libre de dominación'.

\section{d) Transferencia de sujetos gramaticales}

Cuando se habla de Nachdenken ... no basta con catalogarla como una narración en primera persona. Los constantes cambios de sujeto gramatical —ich-sie-wir-ihr - denotan 'la dificultad de decir yo', tema central de la obra. La elección de utilizar una narradora en primera persona se entiende como una gran paradoja en una novela donde se trata el problema de la falta de identidad. La propia protagonista utiliza en sus escritos la primera persona $^{38}$, pero también existen abundantes ejemplos donde Christa T. habla de sí misma en

\footnotetext{
${ }^{33}$ Aunque utiliza el condicional que podría remitir a hipótesis, también hace uso del presente y del pasado así como del estilo directo que nos indican todo lo contrario
}

${ }^{34}$ El material que se supone iba a ayudar a la narradora a recordar, más bien añade datos nuevos que ella desconocía y que llegan a contradecirla: Nachträglich bin ich über Ihre Tagebücher erschrocken. Ich könnte mich fragen, warum ich nichts bemerkt habe, oder fast nichts. (47)

${ }^{35}$ Por ejemplo en las págs. 56 y 181.

${ }^{36}$ Niemals hat sie auseinanderhalten können, was nicht zusammengehört: (...) die nächtlichen unbegrenzten Träume und die begrenzten Taten im Tageslicht (...). (66)

${ }^{37}$ (...) sie hat genau die Art Phantasie gehabt, die man braucht, sie (unsere Welt) zu erfassen (...). (53)

${ }^{38}$ Die hier sitzen, sind Verfluchte, und ich mit ihnen. Nur daß ich nicht mehr aufstehen kann, wenn das Lied nun kommt: Da ist es. Ich bleibe sitzen. Ich drücke das Kind fest an mich. (23-24) (Subravado mín). 
tercera persona ${ }^{39}$ produciéndose lo que Stanzel (1991: 242-257) denomina personale Erzählsituation.

¿Por qué se produce esta transferencia de personas? Thomassen (1977: 142) lo explica basándose en el proceso de búsqueda de identidad en el que se halla inmersa la protagonista. Según esta estudiosa, Christa T. prefiere escoger, a veces, la tercera persona con el fín de acortar distancias entre la realidad y la posibilidad, o en otras palabras, entre el yo presente y el posible yo futuro —el que está en proceso de desarrollo-. A esta explicación creo que es de sumo interés añadir la tesis que ha desarrollado Clausen (1980: 324) al respecto y que demuestra la percepción femenina con la que se trabaja en la novela. En su opinión, mientras que la primera persona no expresa género -únicamente por el contexto-, la tercera persona es un pronombre con género marcado, en este caso el femenino. Por consiguiente, escribir en tercera persona no es sólo una técnica por la que la protagonista intenta aproximar el yo real al yo posible, sino que además es un modo de evitar que la voz de la mujer como tal desaparezca en un yo generalizador. El uso de sie es la técnica que capacita al yo femenino a hablar y a sobrevivir al ich-wir-man pronombres sin género marcado. A través del uso que su amiga ha hecho de la tercera persona la narradora descubre el secreto de ésta ${ }^{40}$.

Por otra parte, la narradora utiliza la primera persona en determinadas circunstancias, sobre todo cuando ésta aparece como una entidad independiente que observa desde una perspectiva externa ${ }^{41}$. Este punto de vista exterior que adopta la narradora hace posible que hable sobre hechos futuros en relación al tiempo narrado ${ }^{42} \mathrm{y}$, por lo tanto, sobresalga el carácter omnisciente de la narradora ${ }^{43}$. En otras ocasiones el yo de la narradora —aunque con autonomía propia - se inserta de modo incidental para distanciarse de la protagonista ${ }^{44}$.

Sin embargo, es importante destacar que el ich de la narradora, a veces, también se fusiona con el de la protagonista: Wie wüßte ich sonst davon? (26). Esta pregunta aparece al final de un pasaje narrado desde la perspectiva interna de Christa T. en tercera persona. El cambio de tercera a primera persona logra que ambas entidades aparezcan yuxtapuestas en esa pregunta. Como explica Clausen (1980: 323), la narradora comparte el dolor y la pena que manifiesta Christa $\mathrm{T}$. en sus notas ${ }^{45}$, tanto que decide intervenir en ese lamento. $\mathrm{Al}$

\footnotetext{
${ }^{39}$ Según Garrido (1993: 141), en las formas narrativas autobiográficas es relativamente frecuente la ocultación del yo tras una tercera persona manteniéndose en este caso la identidad narrador-personaje. Christa T. fühlt eine Kälte den Rücken hochsteigen, bis in den Kopf. Sie wendet sich ab, geht weg. Nicht Ekel kommt - Trauer. Später laufen $\underline{i h r}$ auch die Tränen übers Gesicht, sie hockt sich auf den Ackerweg und weint. (108) (Subrayado mío).
}

${ }^{40}$ Ich begreife das Geheimnis der dritten Person, die dabei ist, ohne greifbar zu sein, und die, wenn die Umstände ihr günstig sind, mehr Wirklichkeit auf sich ziehen kann als die erste: ich. (167)

${ }^{41}$ In meinem letzten Brief an sie -ich wußte, es war der letzte, und ich hatte nicht gelernt, letzte Briefe zu schreiben-fiel mir nichts anderes ein, als ihr vorzuwerfen, daß sie gehen wollte, oder mußte. (8) (Subrayado mío)

${ }^{42}$ Sie wird den Brief lesen wie eine alte, fast vergessene Geschichte, und ich werde seinen Brief mit ihren übrigen Papiere bekommen. (65)

${ }^{43}$ Desde la perspectiva interna esto le sería imposible, porque participaría de la acción que narra con lo cual su conocimento de los hechos sería limitado.

${ }^{44}$ (...) in den Skizzen, die ich gefunden habe, (...). (25) (Subrayado mío)

${ }^{45}$ Las dos pertenecen a la generación de niños y jóvenes formados bajo la tutela del Nacionalsocialismo. 
fusionarse estas dos identidades Wolf utiliza un medio estilístico con el que evita que la narradora domine sobre la protagonista y con el que, además, resalta la experiencia común y solidaridad entre mujeres (Clausen, 1980: 324).

La permanente variación de sujetos gramáticales denota con claridad la cuestión de la búsqueda de identidad, una circunstancia que la narradora aprovecha para adoptar dos puntos de vista dispares dentro de la estructura de la novela: la identificación o el alejamiento respecto a Christa T. (Einhorn, 1978: 455). De este modo la narradora participa en un momento dado de las vivencias, esperanzas, ideales y desengaños de la protagonista y unas líneas más adelante narra un suceso desde una perspectiva externa alejada completamente de Christa $\mathrm{T}$.

La ambigüedad se incrementa en el texto cuando se introduce el pronombre impersonal man como sujeto gramatical ${ }^{46}$. Aunque parezca un tanto contradictorio que Wolf haga uso de este pronombre pseudo-genérico — siendo que, como ya se ha explicado, emplea el sie tan conscientemente- su fín es el de no particularizar tanto en la protagonista o en ella misma, sino llegar también a los lectores (Thomassen, 1977: 59). Además, el uso de man en un contexto donde cabría esperar un sie, sirve, una vez más, para romper con la dicotomía narradora-sujeto perceptor / protagonista-objeto percibido (Clausen, 1980: 323).

En ocasiones no existe dificultad alguna para identificar man con una o varias personas gracias al contexto ${ }^{47}$, pero otras veces esto se puede convertir en una ardua tarea para los lectores a los que les resulta imposible identificar man con personaje alguno: So mußte es diese verbotene Liebe sein, oder wie man es nennen soll. ${ }^{48}$ (155) Este pronombre impersonal puede emplearse no sólo para referirse a una sola persona, sino también a varias: Einmal wird man wissen wollen, wer sie war, wen man da vergi $\beta t_{.}{ }^{49}$ (182) En este ejemplo man se identifica con la narradora, pero además incluye a los lectores; es más, a otro nivel incluso puede incluir a la autora y a los lectores (Thomassen, 1977: 59).

Esta misma confusión de significados tiene lugar cuando la persona gramatical es wir. La función integradora de este pronombre hace que, además de representar la unión entre la narradora y la protagonista y afirmar su conjunción de pensamiento ${ }^{50}$, a veces abarque también a toda esa generación de jóvenes que junto con la narradora y Christa $T$. creía firmemente en la ideología marxista ${ }^{51}$; en otras ocasiones llega incluso a incorporar a la $\mathrm{RDA}$ en general. También hay ejemplos en los que wir se refiere a grupos más reducidos en

${ }^{46}$ También en el caso de 'einem, er', etc.

${ }^{47}$ Schwarzrotgoldene Fahnen brennen, da ist man fünf Jahre, und die Schwester, wenig älter, kommt mit schreckensbleichem Gesicht und zerrt einem nach Hause, man geht mit und erwartet das Schlimmste. (22) En este ejemplo se sabe que el man corrresponde a la protagonista porque más adelante se menciona el hipocorístico Krischan.

${ }^{48}$ (Subrayado mío)

49 (Subrayado mío)

${ }^{50} \mathrm{Da}$ wir einander nicht fragten, warum wir uns erst jetzt, erst hier ansprachen, war das erste Zeichen der alten oder schon der neuen Vertrautheit. (28) (Subrayado mío)

${ }^{51}$ Wir müssen schon einiges dazu tun, um alle lebenswert zu leben. Man muß bereit sein, eine gewisse Verantwortung zu ühernehmen. (54) (Suhravadn mín) 
los que la narradora - sin Christa T.- incluye bien a un grupo de amigos ${ }^{52}$, bien a los posibles lectores ${ }^{53}$. Cuando la narradora incluye a los lectores en el wir provoca un proceso de identificación, aunque no siempre es así. Esto conduce a que los lectores experimenten una continua tensión entre la identificación y el distanciamiento.

El distanciamiento más evidente se produce cuando entra en juego el sujeto gramatical $i h r$ cada vez que la narradora reflexiona, pregunta, ...: Ihr habt gefragt, was ich vorzuweisen hätte. Nun denn: den Ton dieser Seiten, als Beispiel. Sie redet, daß man sie sieht. ${ }^{54}$ (33) El uso de $i h r$ desvía a los lectores de una posible identificación con Christa T. o con la narradora, pero, a la vez, se les invita a que participen en el proceso de recuperación de la persona desaparecida (Thomassen, 1977: 62).

Como se ha podido observar, esta técnica presenta todo un abanico de posibles interpretaciones que reflejan la inseguridad producida por la carencia de una identidad definida.

\section{e) Supresión de las coordenadas espacio-temporales}

La novela se aparta del estilo narrativo lineal de la forma tradicional. Se subvierte el orden cronológico y se ofrece una imagen fragmentada de la realidad que comprende todo un mosaico de planos temporales. La estructura de la novela está basada en el recuerdo que no obedece al criterio de sucesión (principio/medio/fín), sino al de asociaciones (en la memoria todo ocurre simultáneamente), de ahí el aspecto 'inconexo' del texto. El recuerdo de la narradora se interrumpe por frecuentes retrospectivas y anticipaciones además de por las digresiones reflexivas y comentarios que la narradora gusta de dirigir a los lectores; por ello, lo único que hace la cronología es estorbar, como admite la propia narradora ${ }^{55}$ : Szenenwechsel, Sprung von sieben Jahren, die Chronologie stört (109).

Por un lado se observa un tiempo de narración que corresponde a los años 1967/68. Este plano temporal ${ }^{56}$ en presente contiene reflexiones y comentarios sobre las vivencias de la protagonista, así como sobre la difícil tarea de escribir. El plano de reflexión aparece entremezclado con el plano de acción ${ }^{57}$, que se encarga de recuperar el pasado de la narradora y de Christa T. utilizando lógicamente formas verbales pretéritas. Ello conduce a

\footnotetext{
${ }^{52}$ Sie hat an unseren Gesprächen teilgenommen, jenen herrlichen ausschweifenden nächtlichen Gespräche über die Beschaffenheit des Paradieses, (...). (54) (Subrayado mío)

${ }^{53}$ Nehmen wir an, ihre Freude wäre echt. (48) (Subrayado mío)

${ }^{54}$ (Subrayado mío)
}

55 Garrido (1993: 165-66) destaca la importante relación del narrador con el tiempo que depende fundamentalmente de la perspectiva adoptada. La ya comentada fluctuante posición de la narradora entre situación narrativa autorial y personal conlleva un cambio en la perspectiva de externa a interna respectivamente. La externa, faculta una visión global del tiempo, con lo cual la narradora tiene vía libre para hablar del pasado, presente o futuro. Desde la interna, en cambio, la narradora-personaje ha de ceñirse a lo que perciben sus sentidos en lo que a visión temporal se refiere, así, su posición sólo le permite hablar del presente que está viviendo. En consecuencia, el cambio en la perspectiva narrativa va inevitablemente acompañado de un cambio en el plano temporal, incluso lo posibilita.

${ }^{56}$ Correspondería al plano de reflexión cuyo discurso valorativo es muy afín -aunque no exclusivo- al narrador omnisciente (Garrido, 1993: 186).

${ }^{57}$ El tiempo narrado abarca treinta años: de 1933 (Christa T. tenía cinco años) a 1963 (año de su muerte). 
que los límites convencionales entre presente y pasado queden en el olvido. Aún así, aclara Einhorn (1978: 466), Wolf consigue un equilibrio entre el tiempo de narración y el narrado, tanto que el mismo proceso de recordar se convierte en tema narrativo: el presente y el pasado se fusionan en tanto en cuanto se analiza la confrontación de una mujer con la sociedad por otra mujer que recuerda desde el presente. Con esta unión se desea además actualizar el pasado para acercarlo a los lectores (Spinner, 1974: 615). La narradora utiliza el presente para meditar sobre el pasado: ¿ha cambiado el presente respecto del pasado?, y en esta reflexión el pasado se extiende hasta el presente e incluso el futuro.

El juego con la estructura temporal llega al punto en que en un mismo capítulo pueden darse hasta once planos temporales distintos mezclando pasado, presente y futuro $^{58}$ (Einhorn, 1978: 468). Las incursiones en el futuro - deseos, ideales, suposiciones, preguntas - se expresan, tanto en el caso de la narradora como en el de la protagonista, mediante formas verbales futuras ${ }^{59} 0$ condicionales ${ }^{60}$.

La vida de Christa T. - y, en gran parte, la de la narradora - se ofrece de forma fragmentada a lo largo de los veinte capítulos. De hecho el primer capítulo no comienza en 1933, sino en noviembre de 1944 que es cuando la narradora conoce a Christa $\mathrm{T}^{61}$ Las fechas aparecen de modo indirecto, diseminadas a lo largo de la trama y nunca al comienzo de los capítulos; a menudo a los lectores no les cabe otra opción que la de adivinar. A esto se añade la falta de deícticos temporales y la inclusión de partículas portadoras de inseguridad semántica, con lo cual se relativizan aún más los escasos datos temporales de la novela (Thomassen, 1977: 72): Ein grauer Tag jedenfalls, also wohl November ${ }^{62}$ (13).

En cuanto a referencias espaciales también se aprecia un cambio constante ${ }^{63}$ a lo largo de la novela; es más, los continuos saltos en el tiempo exigen a su vez un traslado de escenario: Szenewechsel, Sprung von sieben Jahren ${ }^{64}$ (109). Sin embargo, la narradora se detiene muy pocas veces en describir espacios e incluso llega a confesar que la descripción detallada no le parece importante: An jenem Abend nahm er sie mit zu sich nach Hause. Die Erfindung des Zimmers habe ich aufgegeben, es ist nicht wichtig (118).

La narradora logra conducir a los lectores una vez más hacia la incertidumbre provocada por la falta de referentes espacio-temporales. A Wolf no le interesa mostrar la

\footnotetext{
${ }^{58}$ El capítulo primero así lo ejemplifica.
}

${ }^{59}$ Wie werden wir sein? Was werden wir haben? (99)

${ }^{60}$ Wenn wir uns bloß nicht täuschen lassen von seiner Tüchtigkeit! Denn - wohin würde das führen? (109)

${ }^{61}$ Die Fliegeralarme wurden länger, die Fahnenapelle düsterer und schwächlicher, wir merkten nichts, und darüber wurde es wieder November. (13)

Christa T. fuhr übrigens trotzdem, im Sommer vierundvierzig, mit einer Freundin, auf die ich eifersüchtig war und die ihr abends im Musikzimmer ihrer verlassenen Berliner Wohnung Beethoven vorgespielt hat, bei Kerzenlicht, bis der Alarm kam. (15)

${ }^{62}$ (Subrayado mío)

${ }^{63}$ Christa T. proviene de un pueblo llamado Eichholz (14), estudia en Leipzig (29), hace una excursión a Berlín Este (122), cuando se casa se marcha a vivir a una pequeña ciudad en Mecklenburg (135), construye una casa en algún lugar del mar Báltico (147). 
evolución cronológica del personaje, sino episodios de esa vida que, desde su punto de vista, tienen un significado especial y pueden hacer meditar a los lectores (Thomassen, 1977: 87-88).

A pesar de todo es posible destacar ocasiones en las que el espacio adquiere importancia, haciendo que la narradora se contradiga a sí misma. Estos sitios se corresponden con cambios importantes en la vida de la protagonista: uno, la pequeña ciudad de la region de Mecklenburg a la que Christa T. se traslada recién casada y con una hija recién nacida renunciando a su carrera por decisión propia ${ }^{65}$; otro, la casa que construye la protagonista. Estos lugares captan la atención de la narradora, el ritmo de la narración se ralentiza y se convierten en lo que Garrido (1993: 217) denomina 'depositarios de los afectos del personaje', es decir, símbolos que reflejan la visión que Christa T. tiene del mundo ${ }^{66}$.

Por otro lado, también hay imágenes que se repiten y a las que Thomassen (1977: 79) concede la doble función de unir distintos planos temporales y distintas perspectivas: las reflexiones de la narradora con el presente de la autora ${ }^{67}$.

Curiosamente en los dos últimos capítulos se observa un aumento de las indicaciones temporales ${ }^{68}$ que la narradora utiliza como técnica para concienciar a los lectores del escaso tiempo de vida que le queda a Christa T. (Einhorn, 1978: 468).

\section{f) Metanovela}

Otro rasgo distintivo de la prosa femenina presente en Nachdenken ... es que a menudo tanto la narradora como la protagonista se detienen a analizar las dificultades de la escritura, convirtiendo el proceso de escribir en un importante tema de reflexión (MacPherson, 1981: 11). De esta forma la novela se considera en parte una metanovela.

La literatura femenina entiende el acto de escribir como un medio que ayuda a superar el distanciamiento entre la mujer y la sociedad (Langbehn, 1989/90: 51). A este respecto las posturas de Christa T. y de la narradora son idénticas a la de Wolf. Las tres se esfuerzan por entender y acercarse a la realidad que les rodea y, sin embargo, ésta les decepciona porque no les permite encontrarse a sí mismas; por ello recurren a la escritura como único vehículo de autorrealización. Dichten, dicht machen, die Sprache hilft (21), el juego de palabras evidencia la ayuda que la escritura proporciona a la protagonista para crear una realidad más acorde con su percepción de mujer. Al mismo tiempo, escribir se convierte en su único medio de comunicación, puesto que se había resignado a permanecer callada, inopinante (Hammerstein, 1987: 22): Daß ich nur schreibend über die Dinge komme! (37).

Los intentos de escribir - diarios, cartas, notas, poemas ...- que lleva a cabo la protagonista documentan su búsqueda de identidad ${ }^{69}$, ese yo que la sociedad en la que vive

\footnotetext{
${ }^{65}$ Aber so unwichtig sind die Orte nicht, an denen wir leben. Sie bleiben ja nicht nur Rahmen für unsere Auftritte, sie mischen sich ein, sie verändern die Szene (...). (134)

${ }^{66}$ (...) dieses ganze Haus nichts weiter war als eine Art Instrument, das sie benutzen wollte, um sich inniger mit dem Leben zu verbinden, ein Ort, der ihr von Grund auf vertraut war, weil sie ihn selbst hervorgebracht hatte, und von dessen Boden aus sie sich allem Fremden stellen konnte. (150)

${ }^{67}$ Da knallt der schwarze Kater noch einmal an die Stallwand. Da zerschellen noch einmal die Elsterneier am Stein. Da wird noch einmal der Schnee von einem steifen kleinen Gesicht gewischt. (108)

${ }^{68}$ Nun also der Tod. Der braucht ein Jahr, und dann ist er fertig, (...). (172) (Subrayado mío)
} 
no deja que salga a la luz. No obstante, aunque Christa T. - y con ella la narradora y la autora- está convencida de que su autorrealización sólo es posible a través de la escritura —actividad creadora donde es libre de expresar su subjetividad uniendo pasado, presente y futuro en un todo coherente-, también reconoce lo difícil que le resulta escoger las palabras adecuadas para explicar su punto de vista del mundo que le rodea ${ }^{70}$. Según Hammerstein (1987: 22), la complejidad de escribir está directamente relacionada con la dificultad de decir yo, y esto se debe al problema de tener que expresar una realidad vista desde la perspectiva femenina en un lenguaje configurado hace siglos por el sistema patriarcal. De ahí que Christa T. pregunte en su tesina si es posible -y, si es así, bajo qué circunstancias- autorrealizarse en el arte. Lo que sí consiguen estas tres figuras femeninas a través de la escritura es cuestionar las relaciones de poder existentes y las formas de subjetividad que éstas producen. En este sentido la escritura es un lugar de resistencia y transformación (Weedon, 1997: 241), y así una novela sobre el pasado se convierte en una novela del futuro indicando lo que todavía está por hacer.

\section{g) Predisposición al diálogo}

El uso de un lenguaje muy próximo al oral es otro de los aspectos formales representativos de esta novela. La inmediatez que sugiere esta técnica rompe con la delimitación tradicional entre lenguage escrito y hablado. Se observa un claro deseo de comunicación por parte de la narradora a lo largo de toda la obra. Al comienzo de la mayoría de los capítulos ésta se dirige a los supuestos lectores mediante preguntas, llamadas o exclamaciones y muchos de ellos terminan de igual modo. Su objetivo es el de obligar a los lectores a la meditación.

Esta forma de expresión se corresponde de nuevo con el problema de identidad. La narradora (y la autora), al igual que Christa $\mathrm{T}$. en su día, se encuentra en pleno proceso de configuración del yo, llena de una incertidumbre que le conduce a relativizar la realidad, incertidumbre que ella transmite a los lectores con la intención de forzarles a romper con su pasividad y conformismo respecto al sistema establecido.

La forma abierta de la novela conecta con su tendencia a la oralidad. El relato no aporta respuestas, sólo anima a los lectores a que busquen sus propias soluciones. La narradora provoca en contra del hieratismo que caracteriza a la sociedad de la RDA y, además, exhorta a perseguir los ideales olvidados que la fundamentaron (Schmitz, 1983: 222). A pesar de que la novela acaba con la muerte de la protagonista, ésta no deja de ser esperanzadora porque la lucha que ha sostenido a lo largo de su vida en pro de su individualidad sirve de ejemplo a los lectores. Nachdenken ... finaliza con una pregunta de clara incitación al cambio que en su día se hizo la protagonista y que la narradora y la autora han hecho suya: Wann, wenn nicht jetzt? (182).

\section{h) Otras formas de relativización}

A los medios de mostrar la inseguridad en la que viven las tres entidades femeninas de la obra es obligado añadir otras técnicas que ayudan a realzar aún más, si cabe, la relativización que prima en todo el texto.

\footnotetext{
${ }^{69}$ Aber was tu' ich denn! Endet ein solcher Brief. (55) En otra de las cartas que envía a su hermana confiesa ich weiß nicht, wozu ich da bin (72)
}

${ }^{70}$ Sie hatte Angst vor den ungenauen, unzutreffenden Wörtern. (168) 
En general se prefieren las oraciones paratácticas, evitando así las correspondencias de la lógica causal que son la base de la literatura convencional. A esta escasez de oraciones subordinadas causales se contrapone una avalancha de oraciones subordinadas condicionales con sus connotaciones hipotéticas que se manifiestan sobre todo en las abundantes preguntas diseminadas en la novela.

El uso de verbos modales con significado subjetivo contribuye a la configuración de la percepción individual de la realidad, utilizados además en la forma condicional, subrayan la falta de certeza que inunda a la narradora. Partículas enfáticas del tipo ja/doch/wohl/aber, palabras polisémicas ${ }^{71}$ y expresiones de incertidumbre ${ }^{72}$ están ahí para transmitir a los lectores el sentimiento de inseguridad de estas tres mujeres. La narradora también llega a sacar frases escritas por Christa $T$. de su contexto original para llevarlas al presente narrativo y dotarlas así de un nuevo significado: Wann, wenn nicht jetzt? (100 y 181).

\section{CONCLUSIONES}

A lo largo del presente trabajo se ha podido comprobar cómo Nachdenken ... incorpora en su haber una serie de componentes formales que se corresponden con la estética femenina propugnada por diversas corrientes teóricas y que contribuyen a llamar la atención sobre los temas expuestos en la obra. La novela atiende a la idea sostenida por Cixous (1980) de que un texto escrito por una mujer siempre debe ser subversivo. El de Wolf lo es no sólo por su contenido, sino también por su forma que (adecuándose al contenido) abandona la lógica lineal tradicional.

Según Rakusa (1984: 280-81) la creatividad femenina exige ir contra toda convención para empezar desde cero. La disolución, destrucción y descomposición que esto trae consigo da pie a un 'desorden' donde se mezcla lo visto con lo leído, lo ocurrido con lo imaginado, lo presente con lo recordado y donde prima lo simultáneo frente a lo lineal; sin embargo este caos aparente es el reflejo de manifestaciones estéticas alternativas. Wolf considera que la verdadera emancipación individual de la mujer —que no tiene nada que ver con la sociopolítica- sólo se consigue a través de la emancipación estética, es decir, la escritora debe utilizar las formas según sea necesario para sus fines.

Escribir desde una conciencia femenina supone un proceso de reconocimiento individual y social (Jurgensen, 1982: 482). Por un lado, ayuda al descubrimiento y al desarrollo de la mujer y, por otro, es un correctivo social que insiste en sacar a la luz una problemática ignorada. Las técnicas narrativas utilizadas por Wolf buscan irritar, provocar y, sobre todo, incitar a la reflexión. La autora crea una mujer insegura y contradictoria como personaje central y emplea formas basadas en la subjetividad femenina. Gracias a esta novela, afirma Langbehn (1989/90: 53), la literatura en la RDA se convierte en portavoz de un yo femenino y gana un formato nuevo e independiente.

Aunque la intención primordial de la autora no era la de escribir una novela feminista, no se puede negar cierta influencia de este movimiento ${ }^{73}$. El relato ejemplifica la

\footnotetext{
${ }^{71}$ Dichten/dicht machen (21); el verbo nachdenken puede tener tres acepciones: erinnern, denken an, im Denken nachfolgen.

${ }^{72}$ Bin wirklich ich gemeint? (57); vielleicht sollte ich ... (117); der Gedanke überrascht mich selbst (77).

${ }^{73}$ A veces aparecen pasajes donde ante todo se defiende a la mujer, por ejemplo, la insistencia de Christa T. a una mujer maltratada por su marido para que se divorcie de él.
} 
discrepancia existente entre ideal y realidad en el destino de una mujer. Wolf no se detiene sólo en esta denuncia, también se atreve a reivindicar el derecho a la individualidad de todas las personas, sean mujeres u hombres: wie können wir Frauen 'befreit' sein, solange nicht alle Menschen es sind $?^{74}$ El sistema establecido de la RDA contemplaba a la mujer y al hombre como meros objetos que debían amoldarse a los mandatos impuestos para configurar la sociedad idílica ${ }^{75}$ ideada por el régimen, y el conformismo se hacía condición indispensable. En consecuencia, los problemas expuestos no son 'sólo de mujeres', puesto que se defiende la consecución de un nuevo socialismo basado en la autorrealización de todos los individuos: mujeres y hombres (Einhorn, 1978: 478). La meta que persigue Wolf es transformar la idea socialista del nosotros en el yo, hacer que las personas vuelvan a ser sujetos con opinión propia (Langbehn, 1989/90: 52), y el mejor modo de conseguirlo es comenzando por reconocer a la mujer como ser independiente a través de su obra. En suma, a Wolf la escritura le sirve para mostrar su inconformismo, le proporciona una voz con la que hacerse escuchar y dar a entender la percepción femenina de las cosas.

\section{BIBLIOGRAFÍA}

H. CIXOUS, Weiblichkeit in der Schrift, (Berlin 1980).

J. ClAUSEN, «The Difficulty of Saying "I" as Theme and Narrative Technique in the Works of Christa Wolf», Amsterdamer Beiträge zur neueren Germanistik, 10 (1980), 319-333.

B. EINHORN, Der Roman in der DDR: 1949-1969. Die Gestaltung des Verhältnisses von Individuum und Geselschaft. Eine Analyse der Erzählstruktur, (Kronberg/Ts. 1978).

W. EMMERICH (ed.), Sarah Kirsch, Irmtraud Morgner, Christa Wolf: Geschlechteraustausch. Drei Geschichten über die Umwandlung der Verhältnisse. (Darmstadt/Neuwied 1980), 101-127.

A. GARRIDO DOMINGUEZ, El Texto Narrativo, (Madrid 1993).

K. HAMMERSTEIN, «Warum nicht Christian T.? Christa Wolf zur Frauenfrage, untersucht an einem frühen Beispiel: "Nachdenken über Christa T." ", New German Review, 3 (1987), 17-29.

F. J. HASSAUER, «Niemals nur "eins" zu sein. Gibt es eine weibliche Ästhetik?», Merkur, 35 (1981), 710-716.

P. Herminghouse, «Wunschbild, Vorbild oder Porträt? Zur Darstellung der Frau im Roman der DDR», en: Hohendahl, P.U./Herminghouse, P. (eds), Literatur und Literaturtheorie in der DDR, (Frankfurt a. M. 1976), 281-334.

S. HilzINGER, Der Wunsch nach "Berührung" - Über das Schreiben von Frauen am Beispiel der DDR-Autorin Christa Wolf, (Marburg 1980/81).

L. IRIGARAY, Das Geschlecht, das nicht eins ist, (Berlin 1979).

M. JURGENSEN, «Was ist Frauenliteratur?», DD, 68 (1982), 480-490.

H. KAUFMANN, «Gespräch mit Christa Wolf», Weimarer Beiträge, (1974), 90-112.

V. LANGBEHN, «Vom Feminismus zum Postmarxismus? Christa Wolfs "Nachdenken über Christa T.” », New German Review, 5,6 (1989/90), 43-55.

\footnotetext{
74 “Berührung” (1984a: 19).
}

${ }^{75}$ Además, esa imagen modélica de sociedad ha sido creada exclusivamente por hombres, ninguna mujer tomó parte en ella. va que la cúpula del nartido en el noder estaha formada sóln nor anuéllnc 
PH. LEJEUnE, Le pacte autobiographique, (Paris 1975).

S. LENNOX, «"Der Versuch, man selbst zu sein". Christa Wolf und der Feminismus», en: Paulsen, W. (ed.), Die Frau als Heldin und Autorin. Neue kritische Ansätze zur deutschen Literatur, (Bern/München 1979), 217-222.

— «Nun ja! Das nächste Leben geht aber heute an" Prosa von Frauen und Frauenbefreiung in der DDR», en: Hohendahl, P.U./Herminghouse, P. (eds), Literatur der DDR in den siebziger Jahren, (Frankfurt am Main 1983), 224-258.

M. LovE, «Christa Wolf and Feminism: Breaking the Patriarcal Connection», New German Critique, 16 (1979), 31-53.

M. MATHEJA-THEAKER, Alternative Emanzipationsvorstellungen in der DDRFrauenliteratur (1971-1989). Ein Diskussionsbeitrag zur Situation der Frau, (Stuttgart 1996).

K. MCPHERSON, «Christa Wolf in Edinburgh: An Interview», GDR Monitor, 1 (1979), 112.

— «In Search of a New Prose», New German Studies, 9 (1981), 1-13.

M. E. O'BRIEN, «The Divided Woman: Female Protagonists in Contemporary GDR Literature», New German Review, 1 (1985), 41-54.

I. RAKUSA, «Frau und Literatur - Fragestellungen zu einer weiblichen Ästhetik», en: Köppel, C./Sommerauer, R. (eds), Frau - Realität und Utopie, (Zürich 1984).

R. SCHMIDT, Westdeutsche Frauenliteratur in den 70er Jahren, (Frankfurt a. M. 1982).

D. SCHMITZ, Weibliche Selbstentwürfe und männliche Bilder. Zur Darstellung der Frau in DDR-Romanen der siebziger Jahre, (Frankfurt a. M./ Bern/ New York 1983).

M. L. SiguÁN BOHEMER, «"Hablar con mi propia voz: lo máximo". Mitología y feminismo en la Casandra de Christa Wolf», en: Carabí, A./Sagarra, M. (eds.), Mujeres y Literatura, (Barcelona 1994), 137-151.

K. H. SPINNER, «Prosaanalysen: Aus Christa Wolf, "Nachdenken über Christa T.», Literatur und Kritik, (1974), 614-621.

J. P. Stanley/ S. J. WolfE, «Toward a Feminist Aesthetic», en: Chrysalis: A Magazine of Women's Culture, 6 (1978), 57-71.

F. K. STANZEL, Theorie des Erzählens, (Göttingen 1991).

A. StePhan, «The Emancipation of Man. Christa Wolf as Woman Writer», GDR Monitor, 2 (1979/80), 23-32.

- Christa Wolf, (München 1991).

D. TATE, The East German Novel. Identity, Community, Continuity, (Bath 1984).

CH. Thomassen, Der lange Weg zu uns selbst: Christa Wolfs Roman „Nachdenken über Christa T." als Erfahrungs- und Handlungsmuster, (Meisenheim am Glan 1977).

M. WANDER, "Guten Morgen, du Schöne." Frauen in der DDR: Protokolle, (Darmstadt/Neuwied 1984).

- Leben wär eine prima Alternative. Tagebuchaufzeichnungen und Briefe, Wander, F. (ed.), (Darmstadt/Neuwied 1980).

CH. WeEDON, «Reading Christa Wolf», en: Weedon, C. (ed.), Post-War Women's Writing in German, (Providence 1997), 223-242.

CH. Wolf, «Ich bin schon für eine gewisse Maßlosigkeit.» Christa Wolf im Gespräch mit W.F. Schoeller, en: Sauer, K. (ed.), Materialienbuch, (Darmstadt/Neuwied 1980a), 5363.

- Büchner-Preis-Rede, (Darmstadt/Neuwied 1980b). 
- Voraussetzungen einer Erzählung: "Kassandra", Frankfurter Poetik-Vorlesungen, (Darmstadt/Neuwied 1983).

— «Berührung: Ein Vorwort», en: Wander, M. (ed.), "Guten Morgen, du Schöne." Frauen in der DDR: Protokolle, (Darmstadt/Neuwied 1984a), 9-19.

- «Selbstinterview», en: Lesen und Schreiben: Neue Sammlung. Essays, Aufsätze, Reden, (Darmstadt 1984b), 69-84.

— «Lesen und Schreiben», en: Lesen und Schreiben: Neue Sammlung. Essays, Aufsätze, Reden, (Darmstadt 1984c), 9-48.

- Nachdenken über Christa T., (München 1991).

V. Woolf, A Room of One's Own, (London 1929). 
